\title{
Ginette Michaux, De Sophocle à Proust, de Nerval à Boulgakov: essai de psychanalyse lacanienne
}

\section{Gabriella Bosco}

\section{(2) OpenEdition}

1 Journals

\section{Edizione digitale}

URL: http://journals.openedition.org/studifrancesi/8140

DOI: 10.4000/studifrancesi.8140

ISSN: 2421-5856

\section{Editore}

Rosenberg \& Sellier

\section{Edizione cartacea}

Data di pubblicazione: 1 juillet 2009

Paginazione: 463

ISSN: 0039-2944

\section{Notizia bibliografica digitale}

Gabriella Bosco, «Ginette Michaux, De Sophocle à Proust, de Nerval à Boulgakov: essai de psychanalyse lacanienne», Studi Francesi [Online], 158 (LIII | II) | 2009, online dal 30 novembre 2015, consultato il 12 janvier 2021. URL: http://journals.openedition.org/studifrancesi/8140 ; DOI: https://doi.org/10.4000/ studifrancesi.8140

Questo documento è stato generato automaticamente il 12 janvier 2021.

\section{(c) $(1) \ominus$}

Studi Francesi è distribuita con Licenza Creative Commons Attribuzione - Non commerciale - Non opere derivate 4.0 Internazionale. 


\title{
Ginette Michaux, De Sophocle ̀̀ Proust, de Nerval à Boulgakov: essai de psychanalyse lacanienne
}

\author{
Gabriella Bosco
}

\section{NOTIZIA}

GINETTE Michaux, De Sophocle à Proust, de Nerval à Boulgakov: essai de psychanalyse lacanienne, Ramonville-Saint-Agne, Éditions Érès, 2008, pp. 239.

1 L'autrice, Ginette michaUX, è psicanalista, membro dell'École de la cause freudienne e insegnante alla Section clinique di Bruxelles, oltre che professore emerito dell'Université de Louvain. Con questo volume intende dimostrare il valore operativo che assume, in letteratura, l'orientamento interpretativo fornito da Lacan. Nell'analizzare uno scritto letterario, Lacan faceva emergere il montaggio finzionale della logica del desiderio e sottolineava come la creazione artistica possa avere effetti analitici sul lettore.

Inserito nella collana «Psychanalyse et écriture» diretta da Jean-Pierre Lebrun (che ha già al suo attivo uno studio di Marie JEMMA-JEJCIC su Jean Cocteau ou l'énigme du désir, sottotitolo: Ce que le poète apprend au psychanalyste, 2006, pp. 304), il saggio di Ginette MichAUX - che si avvale di una presentazione di Pierre Piret dedicata alla nozione lacaniana di "parlêtre" - comporta quattro sezioni. La prima, «Psychanalyse et littérature» (pp. 21-30), fornisce un'introduzione all'orientamento lacaniano e ricorda l'apporto della psicanalisi alla teoria della letteratura. La seconda, «La lettre et le désir» (pp. 33-159), studia lo "sguardo proustiano" in cinque sue modulazioni (l'oggetto perso e la scrittura, l'incontro di Gilberte, l'incontro di Madame de Guermantes, i biancospini e la fotografia); Sylvie di Gérard de Nerval; Moi aussi je suis peintre di André Sempoux; il discorso tragico nel teatro di Sofocle; il primo teatro di Maurice Maeterlinck; l'oggetto d'oro nelle Quinze chansons dello stesso autore e La déchirure di Henry Bauchau. 
3 La terza sezione, dedicata alle «Ecritures de la pulsion de mort» (pp. 163-212) propone lo smontaggio del discorso perverso, ovvero i dibattiti filosofici nell'opera di Sade; si sofferma sull'enigma del lupo mannaro nel Thyl Ulenspiegel; illustra la logica dell'assassinio in Bruges-la-Morte di Georges Rodenbach e quella del doppio in Un homme si simple di André Baillon; e si conclude con un'analisi de La surface de l'eau di Eugénie De Keyser.

4 La quarta e ultima sezione, «Subversions du discours du maître» (pp. 215-229), completa il discorso critico indagando La Nouvelle Héloise di Rousseau dal punto di vista di un uso inedito della tromperie, e Il maestro e Margherita di Bulgakov come un sistema di scrittura che si oppone alla censura tramite il fantastico.

5 Tredici dunque le opere studiate, nell'ottica di snidare la singolarità inventiva di ognuna di esse grazie all'approccio lacaniano e a un agile, convincente ricorso alla psicanalisi applicata. 